not confirmed at the conventional level $[F(1.32)=3.42, .05>p<.10$. The interaction of " $[$ " and " $N$ " did not approach significance $[F(1.32)<1.00]$

The main effect of "trials" was reliable $[F(11,352)=16.50 . \quad p<.001$. Thus, performance improved significantly with practice. In addition, the interaction of "trials" and "I" was reliable $[F(11,352)=2.00, \quad p<.02$. The interaction of "trials" and "..." howerer. did not prove significant $|1| 1 \mid .32\}<1.00 \mid$

Informal records of Ss' behavior while in the goalbox were made and suggest that pronounced and consistent differences existed amon! the groups. Thus. then entering the gualbox. Si in 1 (N2. It) tended to run directly to the dipper cup and rapidly drink the water it contained, thereafter maintaining their orientation toward the reward mechanism for the second or so until the cup was refilled. The Ss in G4 also typically ran to the dipper cup and consumed the water it contained. but seldom remained oriented toward it for the 6 or $7 \mathrm{sec}$ until it was refilled. Rather. they commonly engaged in other. nonconsummatory activites such as running away from the reward mechanism to the retrace door and vigorously manipulating that door with their paws. The frequency of such nonconsummatory responses among Ss in Groups 2 and 3 appeared to be intermediate, while the extremes were provided by Groups 1 and 4.

\section{DISCUSSION}

The primary purpose of the present experiment was to investigate the hypothesis that an important determinant of the reinforcement value or effectiveness of a given reward is the extent to which that reward results in the occurrence of consistent consummatory activity and the supression of other nonconsummatory responses. Of central interest is the finding that Ss that received rewards at the short interval ran faster than $S s$ in the 10-sec groups, which is, of course, consistent with the present interpretation of reinforcement. Since only about $3 \mathrm{sec}$ were required to drink the water in the dipper, Ss in the 4-sec group had to drink quite consistently in order to consume all of the available reward. Conversely, $S$ s in the 10-sec groups had about $7 \mathrm{sec}$, or $70 \%$, of their goalbox confinement time in which to engage in nonconsummatory activities, which could presumably generalize to the runway and startbox and interfere with the instrumental, locomotor response. The Ss in the 10-sec groups were, in fact, observed to engage in a considerable amount of overt motor activity other than drinking and at points distant from the dipper. while Ss in the 4-sec groups showed little or no overt nonconsummatory activity and tended to retain orientation to the dipper thoughout their confinement to the goalbox. There was also a suggestion that Ss ran faster to the smaller total reward per trial ( 2 rewards) than to the larger (10 rewards), although this result failed statistical confirmation. According to the present analysis, the apparent inferiority of the 10-reward Ss might be attributed to the greater opportunity for nonconsummatory activity with 10 interreward intervals than with 2 . Even through 2 rewards had greater "apparent reinforcement value" than 10 , however. it might still be argued that 10 pellets resulted in a greater "incentive value." which was obscured by response competition. In short, the failure to obtain a pronounced effect of $\mathrm{N}$ may have been the result of the opposed processes of incentive motivation and response competition (Black, 1969).

\section{REF FRENCES}

BLACK. R. W. Shifts in magnitude of reward and contrast effects in instrumental and selective learning: A reinterpretation. Psychological Review, 1968, 75, 114-126.

BLACK. R. W. Incentive motivation and the parameters of reward in instrumental conditioning. In W. J. Arnold (Ed.), Nebraska simposinm on motiration. Lincoln: L nivervity of Vobratia Press. in press.

BLACK. R. W.. \& FLSTAD, P. Instrumental and consummatory behavior as a function of length of reward period. Psychonomic Science, 1964, 1, 301-302.

CAMMIN, W. Quantitative and qualitative shifts in reward in instrumental conditioning. Unpublished doctoral dissertation, University of South Carolina, 1968.

CILLUFFO, A. F. Rate and frequency of discrete reinforcements as determinants of instrumental performance. Unpublished doctoral dissertation, University of South Carolina, 1969.

CRESPI, L. P. Quantitative variation of incentive and performance in the white rat. American Journal of Psychology, 1942, 55, 467-517.

GUILD, R. E. Incentive motivation in satiated rats. Joumal of Comparative \& Physiological Psychology, 1960, 53, 351-358.

GUTHRIE, E. R. Association and the law of effect. Psychological Review, 1940, 47, 127-148.

HIERS, J. M. Persistence of contrast effects following repeated shifts in reward in instrumental conditioning. Unpublished doctoral dissertation, University of South Carolina, 1968.

PUBOLS, B. H. Incentive magnitude and learning and performance in animals. Psychological Bulletin, 1960, 57, 9-115.

\title{
Effects of chlordiazepoxide on the acquisition of shuttle avoidance in the rabbit ${ }^{1}$
}

DRAKE C. CHISHOLM and JOHN $W$. MOORE, University of Massachusetts, Amherst, Mass. 01002

Rabbits injected with various dosages of chlordiazepoxide showed a decrement in the acquisition of a two-way shuttle-avoidance response. It is suggested that these results are not consistent with the notion that chlordiazepoxide reduces fear.

Earlier research by Chisholm \& Moore 2 showed that chlordiazepoxide (CDP) disrupted performance of a previously acquired shuttle-avoidance task. It was also shown that CDP did not affect discriminative fear conditioning in a situation where tones were paired with inescapable shock, and the effects were tested when the fear CSs were imposed upon avoidance behavior.

Sachs, Weingarten \& Klein (1966) studied the effects of CDP $(15 \mathrm{mg} / \mathrm{kg})$ on the acquisition of a two-way shuttle-avoidance response and found that CDP-injected rats acquired the response faster than did control animals. This finding was in agreement with Zbinden \& Randall's (1967) impressions that CDP attenuates fear and apprehension when the 


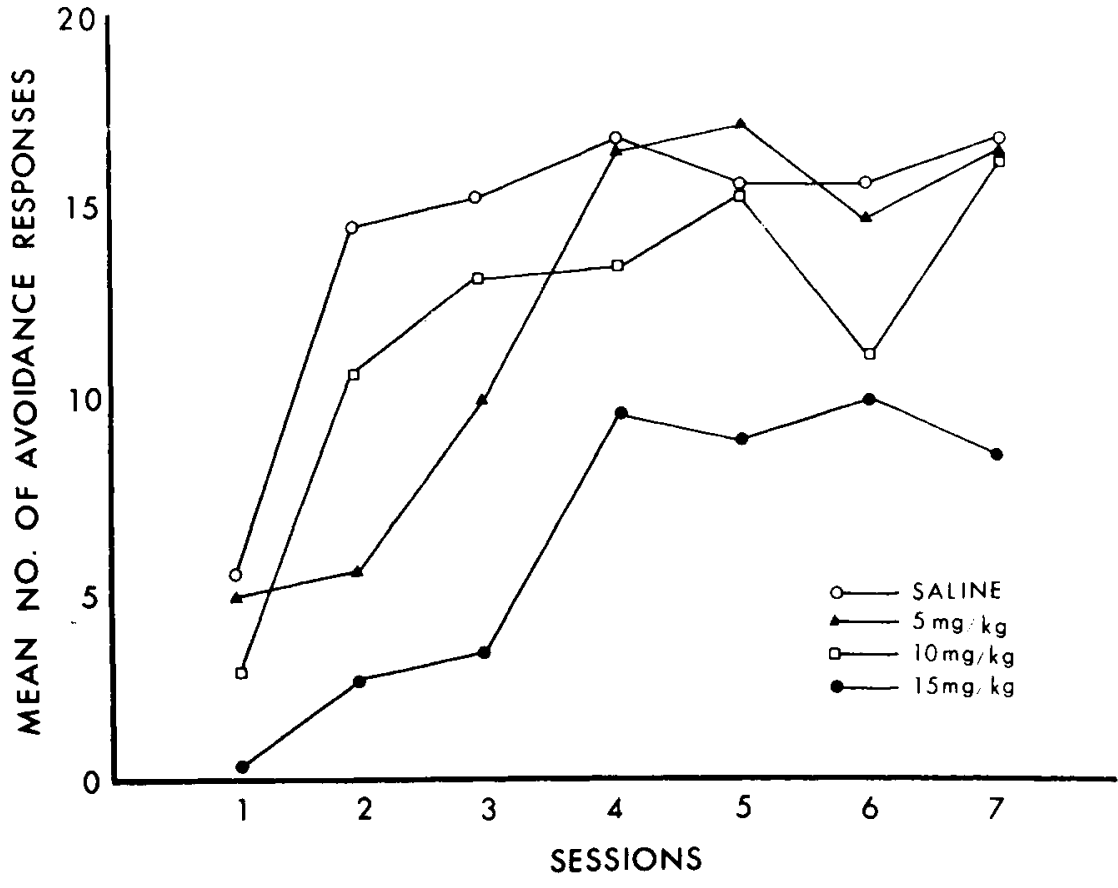

animal is in a conflict situation. That is, the two-way avoidance box is seen as a conflict problem because the animals must either return to the side where they were previously shocked or get shocked for not responding. Animals injected with CDP are said not to be affected by the negative incentive of the approach-avoidance conflict and for that reason acquire the task faster than do no-drug control animals (Feldman, 1968).

The previous finding (Chisholm \& Moore ${ }^{2}$ ) that CDP did not affect discriminative fear conditioning cast doubt on the usefulness of the "decrease in negative incentive" notion to explain the findings of Sachs et al (1966). The purpose of this experiment was to determine if CDP would, in fact, facilitate the acquisition of a shuttle-avoidance response of the rabbit. SUBJECTS

Sixteen New Zealand rabbits, 90-110 days old, had free access to food and water throughout the experiment.

\section{APPARATUS}

The shutlebox was $24 \times 15 \times 23$ in. high, with a 4-in. hurdle in the center. The avoidance $\mathrm{S}^{\mathrm{D}}$ was a compound stimulus consisting of an increase in white noise from 60 to $70 \mathrm{~dB}$ SPL and the onset of two 6.W lights mounted in the top of the box. A Lehigh Valley Electronics LVE 1531 constant-current scrambler was used to deliver the $3-\mathrm{mA}$ US. The shuttlebox was located in a light-shielded room (darkness during the intertrial interval), and both the number and time of each hurdle jump were recorded by $E$ from an adjacent room.
Fig. 1. The mean number of shuttle-avoidance responses for the saline and three drug groups.

\section{DISCUSSION}

The results of this experiment suggest that CDP disrupts the acquisition of shuttle-avoidance behavior in rabbits. These findings also cast doubt on the usefulness of the "decrease in negative incentive" mechanism as an explanatory tool for the acquisition of two-way avoidance tasks (Feldman, 1968). However, the reason for the discrepancy between these findings and the results of Sachs et al (1966) is not clear at this time. Although one might tend to attribute the conflicting results to a species difference, recent work by $\mathrm{Ralph}$ et $\mathrm{al}^{3}$, using rats as Ss, tends to support the results found with rabbits.

A second plausible explanation of the discrepant results suggests that if the $S^{D}$ was not evenly distributed on both sides of the shuttle compartment, the $\mathrm{S}$ may have perceived the two-way shuttle as a one-way avoidance task. Thus, the Ss would not have been in an approach-avoidance situation and the CDP would not be expected to facilitate acquisition according to the reasoning of Feldman (1968). However, the strength of this type of explanation is weakened by the fact that one must assume the imbalance of stimulus cues was present in both this experiment and in the work by Ralph et al. ${ }^{3}$ Therefore, we believe that the procedural differences between Sachs et al (1966) and this experiment may be sufficient to explain the discrepant results. That is, either the 4-day pause between training sessions or the high incidence of initial freezing found in that study may have been the critical factors producing the discrepancy.

\section{REFERENCES}

shuttle response occurred within $5 \mathrm{sec}$, the shock was avoided and the SD was terminated. If Ss shuttled during the US, the shock was escaped and the $\mathrm{SD}^{\mathrm{D}}$ was terminated. The average intertrial interval was $45 \mathrm{sec}$.

\section{RESULTS}

Figure 1 shows the mean number of avoidance responses as a function of days for each of the four groups. The critical data are the first 3 days of acquisition, when the CDP groups were expected to learn the avoidance response faster than the saline group. However, in each case, the CDP groups were slower to learn the avoidance responses than was the saline group. The $15 \mathrm{mg} / \mathrm{kg}$ dosage that previously facilitated acquisition was found to significantly decrease the number of responses in this experiment $(t=3.76$, $\mathrm{df}=6, \mathrm{p}<.01)$. Other differences were not significant.
FELDMAN, R. S. The mechanism of fixation prevention and 'dissociation' learning with chlordiazepoxide. Psychopharmacologia, 1968, 12, 384-399.

SACHS, E., WEINGARTEN, M., \& KLEIN, N. W., JR. Effects of chlordiazepoxide on the acquisition of avoidance learning and its transfer to the normal state and other drug conditions. Psychopharmacologia, 1966, 9, 17-30.

ZBINDEN, G., \& RANDALL, L. O. Pharmacology of benzodiazepines: Laboratory and clinical correlations. In S. Garattini \& P. Shore (Eds.) Advances in Pharmacology. Vol. 5. New York: Academic Press, 1967. Pp. 213. 291

$$
\text { NOTES }
$$

1. This research was supported in part by NSF Grant GB 8634. The chlordiazepoxide was supplied by Hoffman-LaRoche, Inc.

2. Chisholm, D. C., \& Moore, J. W. Effects of chlordiazepoxide on discriminative fear conditioning and shuttle avoidance performance in the rabbit. Submitted for publication.

3. Ralph. T. L., Feldman, R. S., \& Carlson, N. R. Unpublished data. 